OPEN ACCESS

Edited by:

Soren K Rasmussen

University of Copenhagen, Denmark

Reviewed by:

Taras P. Pasternak

Albert Ludwig University of Freiburg,

Germany

Stephan Clemens,

University of Bayreuth, Germany

${ }^{*}$ Correspondence:

Wenzhong $X u$

xuwzh@ibcas.ac.cn

Longhua Wu

Ihwu@issas.ac.cn

Specialty section:

This article was submitted to

Plant Biotechnology,

a section of the journal

Frontiers in Plant Science

Received: 17 November 2016

Accepted: 31 May 2017

Published: 16 June 2017

Citation:

Liu H, Zhao H, Wu L and Xu W

(2017) A Genetic Transformation

Method for Cadmium

Hyperaccumulator Sedum

plumbizincicola

and Non-hyperaccumulating Ecotype

of Sedum alfredii.

Front. Plant Sci. 8:1047.

doi: 10.3389/fpls.2017.01047

\section{A Genetic Transformation Method for Cadmium Hyperaccumulator Sedum plumbizincicola and Non-hyperaccumulating Ecotype of Sedum alfredii}

\author{
Huan Liu',2, Haixia Zhao 1,2, Longhua $W^{3 *}$ and Wenzhong $X u^{1 *}$ \\ ${ }^{1}$ Key Laboratory of Plant Resources, Institute of Botany, Chinese Academy of Sciences, Beijing, China, ${ }^{2}$ University of \\ Chinese Academy of Sciences, Beijing, China, ${ }^{3}$ Key Laboratory of Soil Environment and Pollution Remediation, Institute of \\ Soil Science, Chinese Academy of Sciences, Nanjing, China
}

The present study demonstrates the development of an Agrobacterium-mediated genetic transformation method for species of the Sedum genus, which includes the $\mathrm{Cd} / \mathrm{Zn}$ hyperaccumulator Sedum plumbizincicola and the non-hyperaccumulating ecotype of $S$. alfredii. Multiple shoots were induced from stem nodes of two Sedum plants using Murashige and Skoog (MS) medium containing $0.1 \mathrm{mg} / \mathrm{L}$ cytokinin 6-benzyladenine (6-BA) and $1.0 \mathrm{mg} / \mathrm{L}$ auxin 1-naphthaleneacetic acid (NAA). The shoot primordia were used as direct targets for Agrobacterium infection. Selection on hygromycin was highly effective in generating Agrobacterium-transformed explants. This callus-free procedure allowed us to obtain transgenic plantlets after rooting hygromycin-resistant shoots on phytohormone-free MS medium containing the antibiotic. The presence and expression of the reporter genes gusA and GFP in transgenic plants were confirmed by a real-time polymerase chain reaction, histochemical GUS assays, and confocal microscopy. This reliable method for genetic transformation of Sedum plants will help us to understand gene functions and the molecular mechanisms underlying $\mathrm{Cd}$ hypertolerance and hyperaccumulation in these species.

Keywords: Agrobacterium tumefaciens, genetic transformation, cadmium, hyperaccumulator, multiple shoot buds, Sedum alfredii, Sedum plumbizincicola

\section{INTRODUCTION}

The genus Sedum L. is the most species-rich member of the family Crassulaceae (Nikulina et al., 2016). There are about 420 species (Thiede and Eggli, 2007), most of which can endure harsh environments ranging from very cold to hot temperatures and dry conditions. In response to conditions of drought stress, many Sedum species evolve crassulacean acid metabolism (CAM) system to take up inorganic carbon in the night (Castillo, 1996; Smirnoff, 1996; Winter and Holtum, 2014). Sedums are also usually cultivated as ornamental plants due to their interesting appearance, diversified phenotypes and extensive adaptability. Some sedums, such as Sedum sarmentosum, 
S. lineare, and S. emarginatum, are important medical plants used to treat hepatitis, dysentery, herpes zoster and swelling (Wang et al., 2014). Recently, S. plumbizincicola and population of $S$. alfredii, native to cadmium (Cd)/zinc $(\mathrm{Zn})$ mining areas in Southeast China, were remarkable $\mathrm{Zn}$ and $\mathrm{Cd}$ hyperaccumulators that have high capacity to accumulate, translocate, and tolerate high concentrations of heavy metals (Yang et al., 2004; Wu et al., 2013).

The rare plant species identified as $\mathrm{Cd}$ hyperaccumulators are able to accumulate Cd to $100 \mathrm{ppm}$ or $0.01 \%$ in the dry shoot biomass when growing in their natural habitats (Clemens, 2001; van der Ent et al., 2013). It may be possible in the future to use these plants, or biotechnology based on an understanding of the relevant molecular mechanisms, for phytoremediation of $\mathrm{Cd}$ contaminated environments, to decrease soil toxicity, and/or to enhance crop production (Verbruggen et al., 2009; Hanikenne and Nouet, 2011; Dalcorso et al., 2013; Verbruggen et al., 2013). S. plumbizincicola growing in field soils is able to accumulate high concentrations of $\mathrm{Cd}$ and $\mathrm{Zn}$ in shoots (>400 mg Cd or $10000 \mathrm{mg} \mathrm{Zn} \mathrm{kg}{ }^{-1}$ dry weight, respectively) and has a shoot/root concentration ratio $>1$ (Deng et al., 2007; Liu et al., 2011; Li et al., 2013; Cao et al., 2014; Peng et al., 2017). Therefore, it has a high potential for $\mathrm{Zn}$ and Cd phytoextraction in the field. However, the molecular mechanisms underlying Cd hyperaccumulation in these species have not been thoroughly investigated because of lacking genetic transformation of $\mathrm{Cd}$ hyperaccumulator species, which is crucial to an improved understanding of the genes important in metal hypertolerance and hyperaccumulation (Verbruggen et al., 2013). Arabidopsis halleri (Brassicaceae) is the only $\mathrm{Zn} / \mathrm{Cd}$ hyperaccumulator reported currently accessible to genetic transformation (Hanikenne et al., 2008; Deinlein et al., 2012; Stein et al., 2017), whereas it accumulates a lower concentration of $\mathrm{Cd}$ in its shoots than its roots (Bert et al., 2003). To our knowledge, the only reported Sedum species accessible to genetic transformation is S. erythrostictum (Yoon et al., 2002). Therefore, the development of genetic transformation protocols for dissecting the underlying molecular mechanism in these hyperaccumulators is necessary. In this work, we successfully developed an efficient method for genetic transformation of Sedum species (Crassulaceae), including the Cd hyperaccumulator S. plumbizincicola and the non-hyperaccumulating ecotype of $S$. alfredii.

Choosing a good target tissue is critical for stable plant transformation (Karami et al., 2009). Callus induction and plant regeneration are important steps in the procedure; however, callus can be genetically unstable and regeneration from callus may result in somaclonal variation (D’Amato, 1977; Skirvin, 1978; Larkin and Scowcroft, 1981). Here, multiple shoot buds were induced from stem nodes of S. plumbizincicola and S. alfredii, and the shoot primordia were used as direct targets for Agrobacterium infection, resulting in efficient transformation. Accordingly, we have established a reliable method for genetic transformation of these Sedum species and this method may be used to facilitate a functional analysis of candidate genes involved in the molecular mechanisms underlying $\mathrm{Cd}$ hyperaccumulation.
TABLE 1 | Effects of plant growth regulators on multiple shoot induction.

\begin{tabular}{ccc}
\hline 6-BA (mg/L) & NAA (mg/L) & Mean No. of shoots per node \\
\hline 0.1 & 0.1 & $1.30 \pm 0.70^{\mathrm{f}}$ \\
0.1 & 0.5 & $2.11 \pm 0.17^{\mathrm{cde}}$ \\
0.1 & 1.0 & $4.40 \pm 0.74^{\mathrm{a}}$ \\
0.1 & 1.5 & $1.74 \pm 0.33^{\mathrm{de}}$ \\
0.5 & 0.1 & $1.36 \pm 0.31^{\mathrm{e}}$ \\
0.5 & 0.5 & $2.50 \pm 0.29^{\mathrm{bcd}}$ \\
0.5 & 1.0 & $2.83 \pm 0.07^{\mathrm{bc}}$ \\
0.5 & 1.5 & $2.37 \pm 0.27^{\mathrm{bcde}}$ \\
1.0 & 0.1 & $3.37 \pm 0.70^{\mathrm{ab}}$ \\
1.0 & 0.5 & $3.06 \pm 1.12^{\mathrm{bc}}$ \\
1.0 & 1.0 & $2.43 \pm 1.08^{\mathrm{bcd}}$ \\
1.0 & 1.5 & $3.41 \pm 0.57^{\mathrm{ab}}$ \\
\end{tabular}

The results were obtained 3 weeks after culture. Different letters indicate that mean numbers of shoots are significantly different at the 0.05 probability level.

\section{MATERIALS AND METHODS}

\section{Plant Materials and Optimization of Conditions for Shoot Induction}

Stems from the non-hyperaccumulating ecotype of $S$. alfredii and the $\mathrm{Cd}$ hyperaccumulator S. plumbizincicola were used as explants for shoot induction. Freshly collected stems were first washed with water and then with $75 \%(\mathrm{v} / \mathrm{v})$ ethanol for $30 \mathrm{~s}$; they were then washed with sterile water three times. Subsequently, the stems were surface sterilized with $0.1 \%(\mathrm{w} / \mathrm{v})$ mercuric chloride $\left(\mathrm{HgCl}_{2}\right)$ for $6 \mathrm{~min}$ with gentle agitation and then washed at least four times with sterile water. The sterilized stems were cut into segments and nodal segments were selected as explants for shoot induction. The stem nodes were cultured for 3 weeks on Murashige and Skoog (MS) basal medium ( $\mathrm{pH}$ 5.8) supplemented with $3 \%(\mathrm{w} / \mathrm{v})$ sucrose and $0.9 \%(\mathrm{w} / \mathrm{v})$ agar with different concentrations and combinations of phytohormones (Table 1). The explants were sub-cultured every week by aseptically transferring stem nodes to fresh media. Tissue was regenerated from explants by direct organogenesis and the numbers of regenerated shoot buds per node were recorded. The culture conditions were maintained at $25^{\circ} \mathrm{C}$ with a 10 -h light $\left(125 \mu \mathrm{mol} \cdot \mathrm{m}^{-2} \cdot \mathrm{s}^{-1}\right) / 14$-h dark photoperiod. The medium that induced shoots most efficiently was used for the next regeneration. Regenerated shoots were then used for testing explant sensitivity to selective agents (hygromycin B and kanamycin).

\section{Sensitivity of Shoot Buds to Antibiotics}

The antibiotics hygromycin B (catalog number 10843555001, Roche) and kanamycin (catalog number KA0408, Realtimes) were tested for toxicity to shoot bud growth and thereby assessed for their suitability as selective agents. To determine the optimum concentration of each, multiple shoot clusters induced from stem node explants were cultured on a shoot induction medium (MS mediumplus $0.1 \mathrm{mg} / \mathrm{L}$ 6-BA, 1.0 mg/L 1-NAA) (6-BA, catalog number B3408, 
Sigma-Aldrich; 1-NAA, catalog number N0640, Sigma-Aldrich) supplemented with various concentrations of hygromycin B (5, 10, 20, 30, and $40 \mathrm{mg} / \mathrm{L})$ or kanamycin $(50,100,150,200$, and $250 \mathrm{mg} / \mathrm{L})$. Three replicate experiments were performed with at least nine explants cultured for each treatment. The explants were transferred to fresh medium containing the same concentration of antibiotic every week to maintain the appropriate selective pressure. The percentage of surviving explants and optimal antibiotic concentration were evaluated after 3 weeks.

\section{Agrobacterium tumefaciens Inoculation and Plant Regeneration}

The plant plasmid pSN1301 contains the $\beta$-glucuronidase (GUS) reporter gene gusA under the control of the CaMV 35S promoter (Supplementary Figure S1A), while pMDC139-GFP contains an enhanced green fluorescent protein (eGFP) reporter gene GFP driven by double enhanced CaMV 35S promoters (Supplementary Figure S1B).

The A. tumefaciens strain C58 harboring plasmid pSN1301 or pMDC32-GFP was cultured in $5 \mathrm{ml}$ liquid LB medium containing $100 \mathrm{mg} / \mathrm{L}$ kanamycin and $50 \mathrm{mg} / \mathrm{L}$ rifampicin. After shaking overnight at $200 \mathrm{rpm}$ and $28^{\circ} \mathrm{C}, 2 \mathrm{~mL}$ of this suspension was used to inoculate $40 \mathrm{ml} \mathrm{LB}$ medium (containing the same antibiotics) and grown under the same conditions until the O.D.600 reached 0.5-1.0. The bacterial culture was centrifuged at $4000 \mathrm{~g}$ for $10 \mathrm{~min}$ and the pellet was resuspended in $5 \mathrm{ml}$ liquid $\mathrm{MS}$ medium supplemented with $100 \mu \mathrm{M}$ acetosyringone (AS, catalog number D134406 Sigma-Aldrich). This bacterial suspension was used for transformation.

Clusters containing greater than 40 shoots, induced from stem node explants, were used as targets for Agrobacterium-mediated transformation. These multiple-shoot clusters were cut into small pieces, immersed in a suspension of Agrobacteria for $30 \mathrm{~min}$, and mixed manually every $2-3 \mathrm{~min}$ at room temperature. The clusters were then blotted dry using sterile filter paper to remove excess Agrobacteria and cultivated for 3 days at $25^{\circ} \mathrm{C}$ on MS medium (MS medium plus $0.1 \mathrm{mg} / \mathrm{L}$ 6-BA, $1.0 \mathrm{mg} / \mathrm{L} \mathrm{2,4-D,} \mathrm{and} 100 \mu \mathrm{M}$ AS), in the absence of light.

After 3 days, the explants were washed three to four times using sterile water supplemented with $300 \mathrm{mg} / \mathrm{L}$ cefotaxime. They were blotted dry on sterile filter paper and then transferred to selection medium (MS medium plus $0.1 \mathrm{mg} / \mathrm{L}$ 6-BA, $1.0 \mathrm{mg} / \mathrm{L} \mathrm{NAA,} 20 \mathrm{mg} / \mathrm{L}$ hygromycin and $600 \mathrm{mg} / \mathrm{L}$ cefotaxime). The culture conditions were maintained at $25^{\circ} \mathrm{C}$ under a 10-h light/14-h dark photoperiod. The multipleshoot explants were transferred to fresh selective medium every week to maintain appropriate selective pressure and prevent the growth of Agrobacteria. Hygromycin resistant shoots that reached approximately $1 \mathrm{~cm}$ in length were removed and transferred to rooting medium (MS medium plus $30 \mathrm{mg} / \mathrm{L}$ hygromycin and $600 \mathrm{mg} / \mathrm{L}$ cefotaxime). GusA gene expression was assessed in plants that had regenerated roots. Plants with regenerated roots were transferred from selective medium to plastic pots containing soil, vermiculite, and perlite $(2: 1: 1)$.
Shoots were cut from transformed plants and cultured hydroponically in $\frac{1}{4} \mathrm{MS}$ salt solution for rooting. The shoots began to produce roots approximately 1 week later. After a further 2-3 weeks, well-rooted plantlets were transferred to soil.

\section{Histochemical GUS Assay}

Histochemical GUS assays were conducted as described previously (Jefferson et al., 1987). Tissue was cut from putative transformants, or alternatively wild-type plants to use as negative controls, and incubated for $4-6 \mathrm{~h}$ at $37^{\circ} \mathrm{C}$ in GUS assay buffer $(0.5 \mathrm{mM}$ potassium ferri- and ferrocyanide, $100 \mathrm{mM}$ sodium phosphate buffer ( $\mathrm{pH} 7.0), 10 \mathrm{mM}$ EDTA $(\mathrm{pH} 8.0)$, and $0.1 \%(\mathrm{v} / \mathrm{v})$ Triton $\mathrm{X}-100)$ containing $1 \mathrm{mg} / \mathrm{mL}$ $X$-Gluc (catalog number B5285, Sigma-Aldrich). After this incubation, green tissue was repeatedly immersed in 95\% ethanol and boiled to remove chlorophyll. GUS stained tissue was visualized using a Wild M8 Stereozoom microscope (Wild Heerbrugg, Switzerland) and images were recorded using the digital camera RemoteCapture DC system (Canon Inc., Tokyo, Japan). GusA gene expression was assessed in transformed explants after 6 weeks of selection and an additional 3-month culture period, while expression of stable, genome-integrated reporter genes was assessed in transformed plants after rapid propagation.

\section{Visualization of GFP Fluorescence}

Leaves and roots from putative transgenic and wild-type (negative control) plants were examined under a laser scanning confocal microscope (Zeiss LSM 510 meta; Carl Zeiss, Oberkochen, Germany) equipped with a 500-550 nm barrier filter to detect eGFP and $650-710 \mathrm{~nm}$ barrier filter to detect chlorophyll autofluorescence. The presence or absence of green fluorescence was compared in control and putative transgenic plants using the LSM 5 series Image Browser software (Carl Zeiss).

\section{Molecular Identification of Transgenic Plants}

Plant genomic DNA for the polymerase chain reaction (PCR) was isolated from leaves of putative transgenic, or wild-type control, plants using DNA extraction buffer containing urea (7 M Urea, 50 M Tris-HCl [pH8.0], $500 \mathrm{mM} \mathrm{NaCl,} \mathrm{2 \%} \mathrm{SDS)} \mathrm{(Liu}$ et al., 2012). The specific primers used for the gusA gene were: forward $5^{\prime}$-GGTGGGAAAGCGCGTTACAAG-3' and reverse $5^{\prime}$-CGGTGATACATATCCAGCCAT-3'. The PCR reaction was performed under the following conditions: $2 \mathrm{~min}$ at $95^{\circ} \mathrm{C}$, followed by 35 cycles of $30 \mathrm{~s}$ at $94^{\circ} \mathrm{C}, 30 \mathrm{~s}$ at $55^{\circ} \mathrm{C}$, and $1 \mathrm{~min}$ $40 \mathrm{~s}$ at $72^{\circ} \mathrm{C}$, and a final 10 -min extension period at $72^{\circ} \mathrm{C}$. The reaction products were analyzed by electrophoresis on a $1 \%(\mathrm{w} / \mathrm{v})$ agarose gel and visualized using a W/LMS-26E transilluminator (Gel DOC-It ${ }^{\mathrm{TM}}$ 300; UVP Ltd, Upland, CA, United States).

Transgene copy number was estimated by real-time PCR (Bubner and Baldwin, 2004; Alvarez and Ordas, 2013) using the quantitation standard curve method (Ueno et al., 2011). Real-time PCR was performed using the SYBR Premix EX Taq GC Kit (Takara Bio Inc., Kusatsu, Japan) and the ABI 


\section{A Effect of phytohormones on shoot induction}

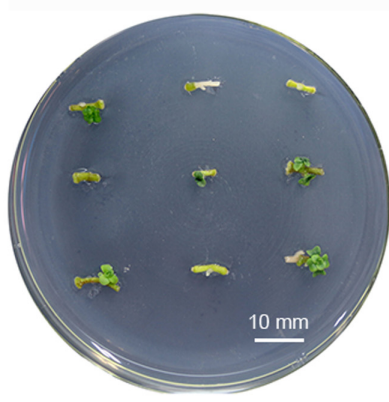

$0.1 \mathrm{mg} / \mathrm{L} 6-\mathrm{BA}$

$0.1 \mathrm{mg} / \mathrm{L} \mathrm{NAA}$

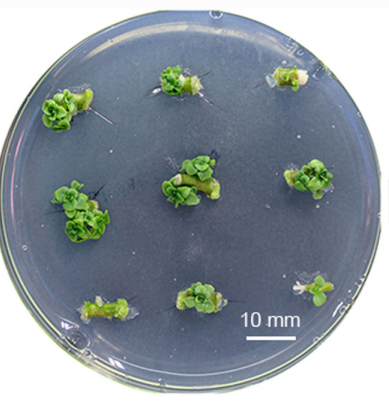

$0.1 \mathrm{mg} / \mathrm{L} 6-\mathrm{BA}$

$1.0 \mathrm{mg} / \mathrm{L} \mathrm{NAA}$

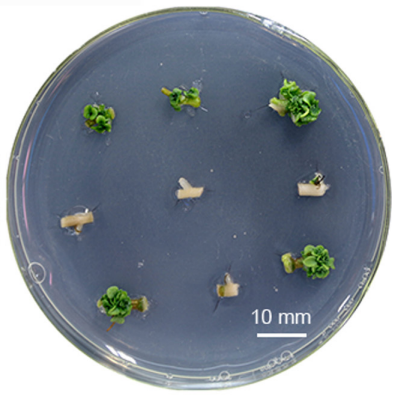

$1.0 \mathrm{mg} / \mathrm{L} 6-\mathrm{BA}$

$0.5 \mathrm{mg} / \mathrm{L} \mathrm{NAA}$

\section{B Multiple shoots induction}

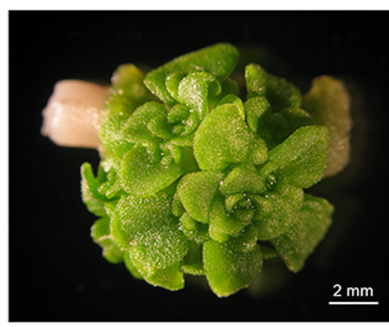

3 weeks

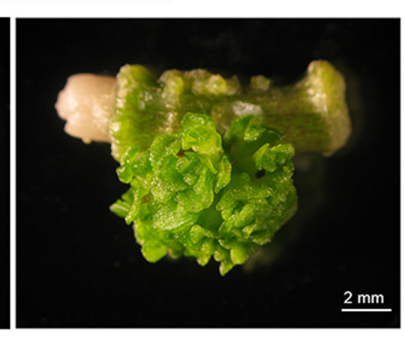

cut off leaves

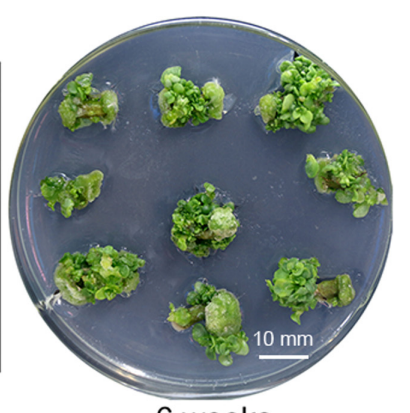

6 weeks

FIGURE 1 | Induction of multiple Sedum alfredii shoots. (A) Stem explants grown on medium containing various concentrations of 6-BA and NAA. (B) Multiple shoots induced on medium containing $0.1 \mathrm{mg} / \mathrm{L} 6-\mathrm{BA}$ and $1.0 \mathrm{mg} / \mathrm{L} \mathrm{NAA}$.

StepOne Plus System (Applied Biosystems, Foster City, CA, United States). The primers used for real-time PCR identification of the gusA gene were $5^{\prime}$-TGTAATGTTCTGCGACGCTCAC$3^{\prime}$ and $5^{\prime}$ - CTTTTTCCAGTACCTTCTCTGCCG-3'. A 50- $\mu \mathrm{g}$ portion of the genomic DNA was used as a template. To generate standard curves and quantify gusA copy number, serial dilutions of plasmid pSN1301 (from copy number: 10-10 ${ }^{6}$ ) were made with wild-type genomic DNA and subjected to real-time PCR. The $C_{\mathrm{T}}$-values for each sample were converted to copy numbers using the standard curves.

Total RNA was isolated from leaves using the Plant RNA Purification Reagent Kit (Invitrogen, Carlsbad, CA, United States). After treatment with DNase I (Sigma-Aldrich, St. Louis, MO, United States), total RNA was reverse transcribed using the M-MLKV Reverse Transcript Kit (Promega, Madison, WI, United States) according to the manufacturer's instructions. GusA gene expression was quantified by real-time RT-PCR using the comparative Ct method (Livak and Schmittgen, 2001).

\section{Statistical Analysis}

For all experiments, data were analyzed by a one-way analysis of variance (ANOVA) using the LSD multiple range test, and differences were considered significant at a level of 5\%. IBM SPSS Statistics (ver. 19; IBM, Armonk, NY, United States) was used for the analyses.

\section{RESULTS AND DISCUSSION}

\section{Induction of Multiple Shoot Buds As Targets for Agrobacterium Infection}

Phytohormones are crucial factors in plant organogenesis and development. The combination of cytokinin 6-benzyladenine (6-BA) and auxin 1-naphthaleneacetic acid (NAA) is highly effective in shoot induction and organogenesis in various Crassulaceae species including: Hylotelephium sieboldii (Nakano et al., 2005), Rhodiola fastigiata (Liu et al., 2006), Kalanchoe blossfeldiana (Smith and Nightingale, 1979; Castelblanque et al., 2010), and Sempervivum tectorum (Dobos et al., 1994). Shoot buds can be induced from stem internode-derived callus in S. alfredii using shoot-induction medium containing 6-BA and NAA (Zhao et al., 2009). In our preliminary trials, axillary buds were generated from $S$. alfredii stem nodes using a shoot bud induction medium containing these two phytohormones. To optimize conditions for producing multiple shoots in $S$. alfredii and to evaluate the effect of combining different concentrations of phytohormones on the number of shoots regenerated, stem node explants were cultured on MS media containing various concentrations of 6 -BA $(0.1,0.5$, and $1 \mathrm{mg} / \mathrm{L})$ and NAA $(0.1,0.5,1$, and $1.5 \mathrm{mg} / \mathrm{L})$. The stem explants were subcultured weekly and adventitious shoot formation was observed at leaf axils (Figure 1A). Medium containing $0.1 \mathrm{mg} / \mathrm{L} \mathrm{6-BA}$ 
A
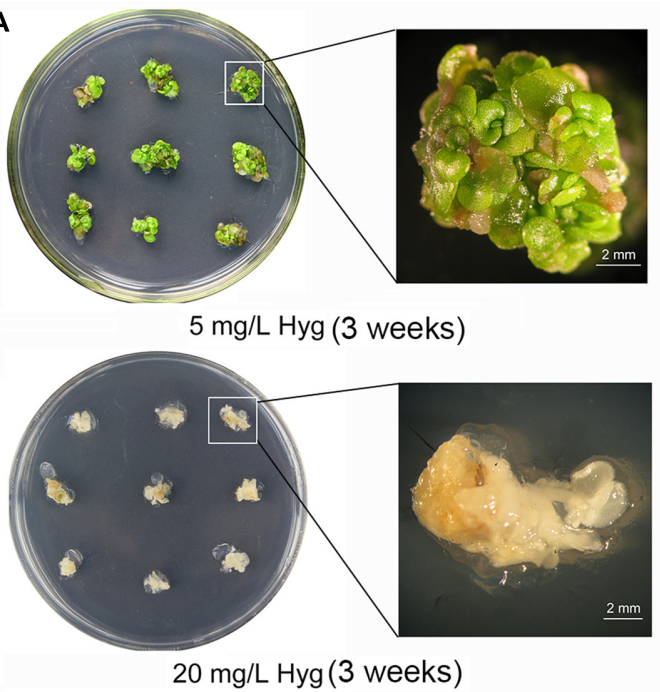

B

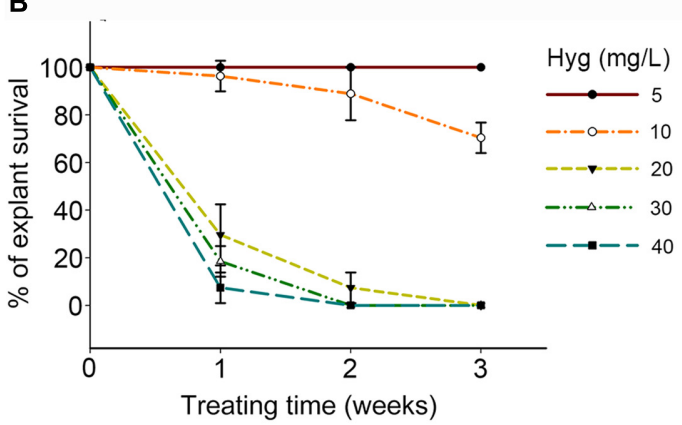

FIGURE 2 | Sedum alfredii sensitive to hygromycin. (A) Growth of explants after 3 weeks on media containing different concentrations of hygromycin (Hyg). (B) Effect of hygromycin concentration and treatment duration on the survival of multiple-shoot explants.

and $1.0 \mathrm{mg} / \mathrm{L}$ NAA produced the maximum number of shoots (on average 4.40 shoots per stem node explant after 3 weeks cultivation - Figure 1A and Table 1), while fewer shoots were observed on media with low concentrations of 6-BA and NAA (Table 1). Concentrations of 6-BA approaching $1 \mathrm{mg} / \mathrm{L}$ were harmful and some explants died; however, surviving explants were able to generate more shoots, especially when higher concentrations of NAA were present in the medium (Figure 1A and Table 1).

After the initial 3-week shoot induction period, stem node explants with more than three shoots were removed and subcultured on MS medium containing $0.1 \mathrm{mg} / \mathrm{L} 6-\mathrm{BA}$ and $1.0 \mathrm{mg} / \mathrm{L}$ NAA (Figure 1B). Multiple shoots began to proliferate. An average of greater than 40 shoots per stem node were observed after an additional three to 5 weeks of culture and the explants formed clusters of shoot apices at each node (Figure 1B).

Multiple shoots were also induced in S. plumbizincicola stem node explants (Supplementary Figure S2). Small shoots emerged from the leaf axils after a 2-week induction period on MS medium containing $0.1 \mathrm{mg} / \mathrm{L} 6-\mathrm{BA}$ and $1.0 \mathrm{mg} / \mathrm{L} \mathrm{NAA}$, and several shoot buds regenerated from explants after 4 weeks of weekly sub-culture. Multiple shoot buds appeared on each S. plumbizincicola stem node after 10 weeks (Supplementary Figure S2), although $S$. alfredii shoot buds developed in a shorter time. The shoot buds were used as targets for Agrobacterium infection.

\section{Sensitivity of Shoot Bud Explants to Selective Agents}

The use of a suitable selective agent at an appropriate concentration is very important in developing an efficient genetic transformation method. The particular selective agent chosen should depend on the plant, as species differ in their sensitivity to selective agents. Hygromycin and kanamycin are the most frequently used antibiotics for generating transgenic plants (An et al., 2014; Nyaboga et al., 2014). The products of selective marker genes can detoxify antibiotics, and as a result transformed plant cells harboring selective marker genes can grow and develop normally in the presence of antibiotics.

The multiple-shoot clusters induced from stem node explants of $S$. alfredii were cultured on MS media containing a concentration gradient of kanamycin (50-250 $\mathrm{mg} / \mathrm{L})$ or hygromycin $(5-40 \mathrm{mg} / \mathrm{L})$. To maintain the potency of each antibiotic, the shoot clusters were sub-cultured onto fresh selection media (with the same antibiotic concentration) every week. The $S$. alfredii shoot tissue had a high tolerance to kanamycin and growth was not inhibited even at a concentration of $250 \mathrm{mg} / \mathrm{L}$ (Supplementary Figure S3A). However, S. alfredii tissue was very sensitive to hygromycin in comparison to kanamycin (Supplementary Figure S3B). The survival of explants declined drastically as the hygromycin concentration increased and treatment time was prolonged (Figure 2 and Supplementary Figure S3B). The growth of multiple shoots was only slightly affected when the concentration of hygromycin was less than $10 \mathrm{mg} / \mathrm{L}$ (Figure 2 and Supplementary Figure S3B). At a concentration of $20 \mathrm{mg} / \mathrm{L}$ hygromycin, the survival of explants was $29.63 \%$ after 1 week, $7.41 \%$ after 2 weeks, and $0 \%$ after 3 weeks (Figures 2A,B). After 2 weeks of culture in medium containing 30 or $40 \mathrm{mg} / \mathrm{l}$, no shoots survived at all, indicating that excessive selection pressure had been applied (Figure 2B).

An appropriate concentration of selective agent is crucial for plant transformation because a suboptimal dose will result in a high frequency of escapes, while an excessive dose will not only kill untransformed tissues, but also inhibit the growth of transformed cells (Datta et al., 1990; Wilmink and Dons, 1993; An et al., 2014). Optimizing the dose of selective agent involves identifying the minimal concentration necessary to prevent regeneration or survival of untransformed tissues, while permitting the development of transformed cells (Song et al., 2012; Nyaboga et al., 2014). Our results indicated that the optimal concentration of hygromycin here was $20 \mathrm{mg} / \mathrm{L}$ and that this was suitable for the selection of transformants from an early stage. These selective conditions were also suitable for S. plumbizincicola. Most untransformed S. plumbizincicola explants turned white and died after 2 weeks on $20 \mathrm{mg} / \mathrm{L}$ hygromycin selective media (Supplementary Figure S2) and 
A Agrobacterium inoculation
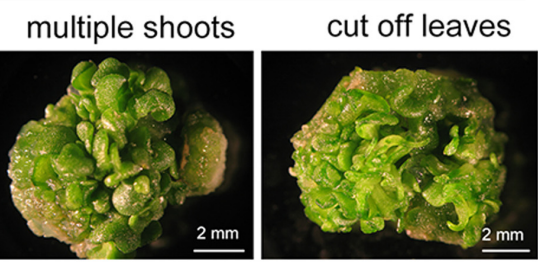

c GUS staining
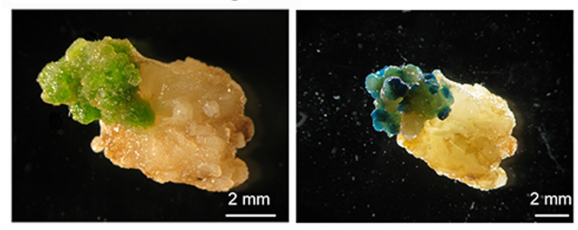

B Hyg selection

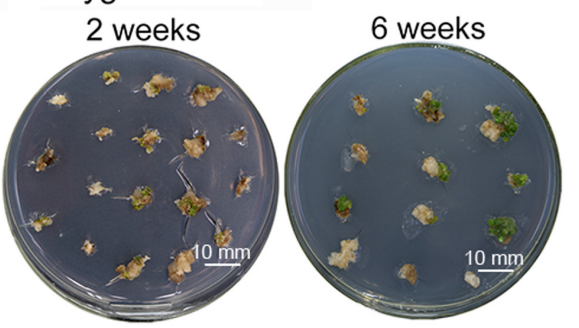

D Root induction
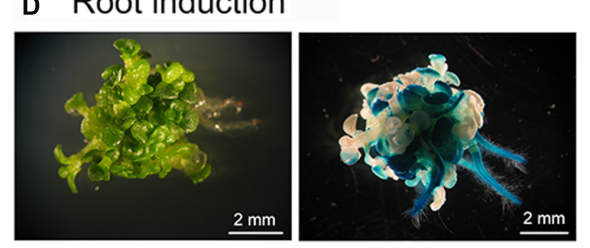

FIGURE 3 | Transformation, selection, and regeneration of Sedum alfredii using multiple-shoot explants. (A) Explants with multiple shoots were isolated and infected with Agrobacterium for 30 min. (B) Selection of explants on hygromycin. Transformed explants remained green and continued to grow on selective shoot induction medium. (C) Regenerated tissue stained for GUS. (D) Root induction. Transgenic shoots rooted in MS medium containing 30 mg/L hygromycin.

no surviving tissue was observed after an additional week of selection.

\section{High-Efficiency Transformation of Sedum Species and Regeneration of Transgenic Plants}

A variety of factors affect the success of Agrobacterium-mediated genetic transformation. These include: the plant genotype, the condition of the explants, the duration of exposure to Agrobacteria, and the tissue culture conditions (An et al., 2014; Nyaboga et al., 2014). Among these factors, having healthy explants is critical for improving the efficiency of T-DNA insertion into genomic DNA and regenerating transformants (Wang et al., 2011). Both gusA and GFP have been widely used as transgenic reporter genes to confirm foreign genes are expressed in transformed plants because detecting their expression is easy and convenient (Jefferson et al., 1987; Prasher et al., 1992). In this study, the clusters of shoot buds induced from S. alfredii or S. plumbizincicola stem nodes were used as targets for Agrobacterium-mediated transformation (Figure $\mathbf{3 A}$ and Supplementary Figure S1). Leaves and elongated shoots were removed from explants with multiple buds and shoot primordia, and the explants were then infected with Agrobacterium strains harboring plasmid pSN1301 or pMDC139-GFP for $30 \mathrm{~min}$ (Figure 3A and Supplementary Figure S1), before being cultivated on MS medium supplemented with $0.5 \mathrm{mg} / \mathrm{L} 6-\mathrm{BA}$, $1.5 \mathrm{mg} / \mathrm{L} \mathrm{2,4-D,} \mathrm{and} 100 \mathrm{mg} / \mathrm{L}$ AS, in the absence of light. After 3 days, the explants were allowed to recover for 2 weeks on shoot induction medium containing $20 \mathrm{mg} / \mathrm{L}$ hygromycin to permit the growth of transformed cells and $300 \mathrm{mg} / \mathrm{L}$ cefotaxime to suppress the growth of Agrobacteria. Non-transformed explants turned white or dark brown, while transformed explants remained green (Figure 3B). Because using a low concentration of selective agent early in the recovery of transformed cells is reportedly beneficial (Burgos and Alburquerque, 2003; Bull et al., 2009; Nyaboga et al., 2014), transformants were first cultured in shoot regeneration medium containing $20 \mathrm{mg} / \mathrm{L}$ hygromycin for 3-4 weeks and then transferred to medium supplemented with $30 \mathrm{mg} / \mathrm{L}$ hygromycin for an additional 3 weeks to effectively eliminate non-transformed cells. This method of selection has previously been effective in transforming other plant species (Sujatha and Sailaja, 2005; Fan et al., 2008; Milojevic et al., 2012). Here, shoots regenerated from the green protuberances on transformed tissue after 6 weeks of selection on the hygromycin-containing shoot induction medium (Figure 3B). At this point, histochemical analysis for GUS expression was performed and strong GUS staining was visible in the shoot buds and green tissue, but not in pale yellow tissue (Figure 3C). Well-developed hygromycin-resistant shoots were then transferred to phytohormone-free MS medium containing $20 \mathrm{mg} / \mathrm{L}$ hygromycin to induce root regeneration (Figure 3D). As expected, only transformed shoots survived and produced roots, while false-positive shoots failed to regenerate roots and died. To produce plantlets suitable for potting, transgenic plants were subcultured on rooting medium for several weeks and plantlets were then transplanted into small plastic pots.

Transformation efficiency was assessed by hygromycin resistance and GUS staining using multiple buds and shoot primordia induced from stem nodes of Agrobacterium-incubated explants. On average, $57.67 \%$ of the $S$. alfredii explants survived and regenerated at least one shoot after selection. Of the regenerated shoots, $82.35 \%$ expressed GUS. However, parallel experiments using S. plumbizincicola explants produced efficiencies of $10 \%$ hygromycin resistance and approximately $75 \%$ of shoots with observable GUS staining. The large difference in transformation efficiencies between these two species may be due to shoot organogenesis being easier in S. alfredii than in S. plumbizincicola. 


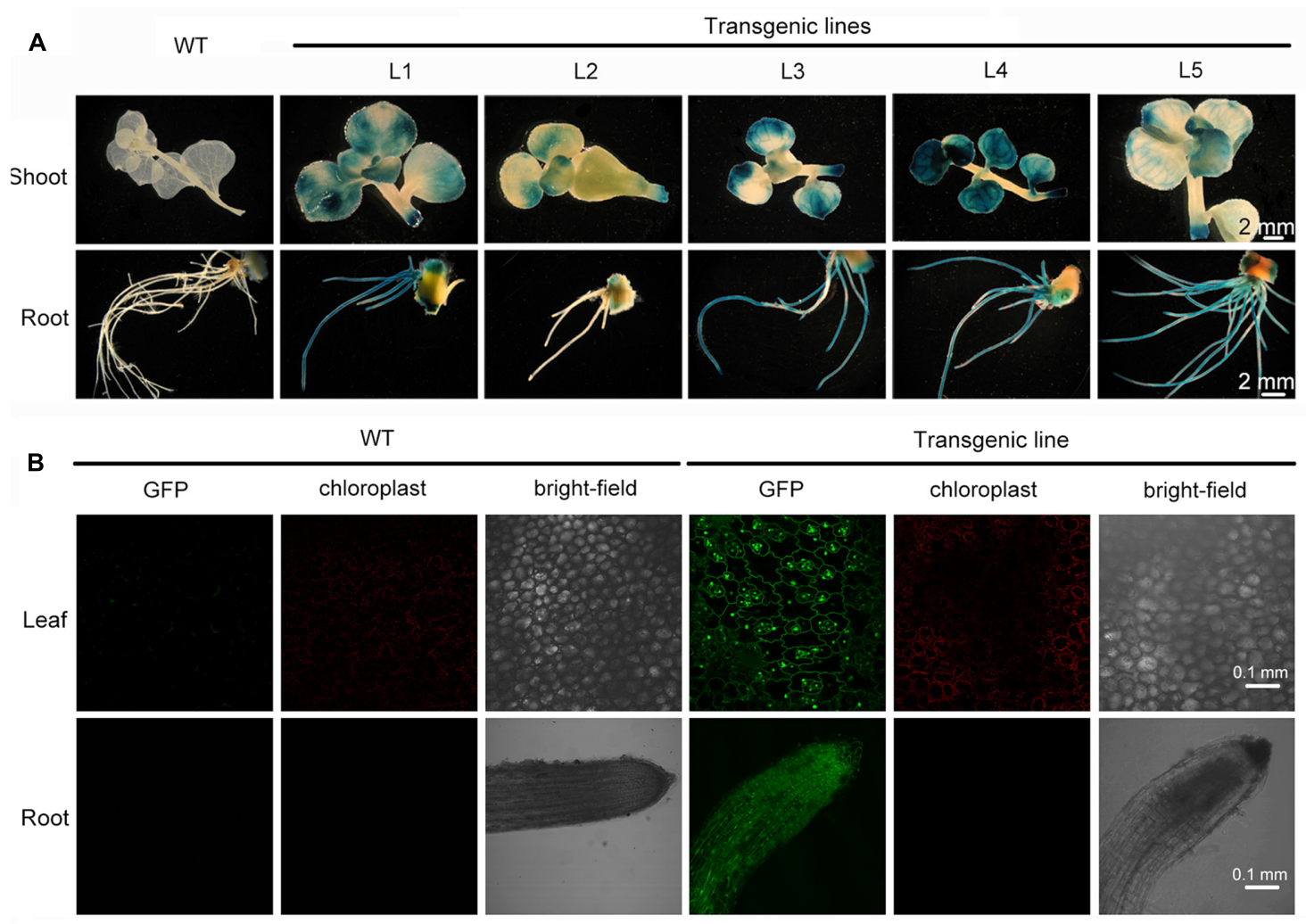

FIGURE 4 | Stable expression of transgenes in rapidly propagated transformants. (A) Stable expression of the gusA gene in WT and different transgenic lines. (B) Stable expression of the GFP gene in leaf and root from WT and transgenic line.

A

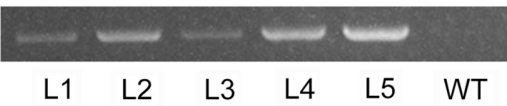

B

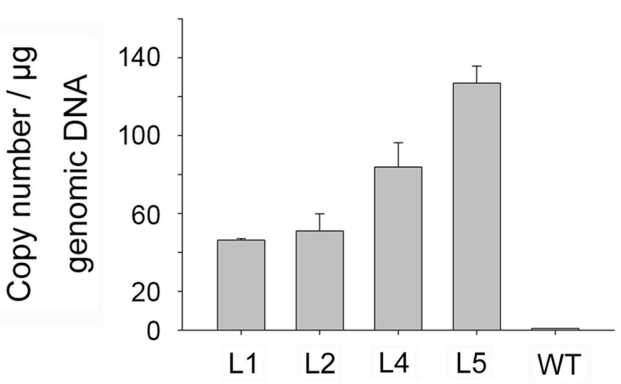

C

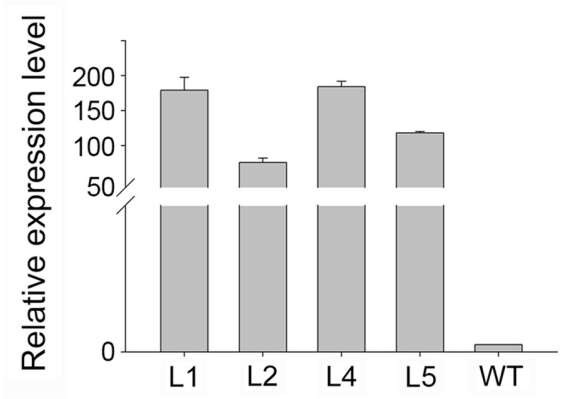

FIGURE 5 | Molecular analysis of transgenic plants. (A) PCR analysis of genomic DNA for the gusA gene in putative transgenic, and WT, plants. (B,C) Real-time PCR analysis of genomic DNA for gusA gene copy number (B) and of cDNA for gusA gene expression level (C)

\section{Stable Expression of the Transgene in Rapidly Propagated Transformants}

Sedum alfredii and $S$. plumbizincicola can easily be made to reproduce asexually or by vegetative propagation. Shoots of putative transgenic plants were removed and cultured for rooting in hydroponic medium containing 1/4 MS basal salts for 1 week. After vegetative propagation, well-rooted plants were randomly selected and transformation was verified by GUS staining analysis. All five of the selected lines stained intensely blue in leaf, stem, and root tissue. Conversely, no blue coloration 
was observed in wild-type plants (Figure 4A), indicating that the gusA gene had stably integrated into the transformed plants' genome and was functional. The intensity of GUS staining varied among the lines (Figure 4A) possibly due to the different locations or copy numbers of the transgene influencing its expression level in the transformants. Another reporter gene, GFP, was introduced by Agrobacterium-mediated transformation into $S$. alfredii explants. GFP expression was observed in leaf and root cells of transgenic plants (Figure 4B), whereas no GFP fluorescence was detected in non-transformed wild-type plants (Figure 4B).

\section{Molecular Identification of Transgenic Plants}

To confirm that foreign genes had been inserted into the transgenic plants, genomic DNA was isolated from GUS positive and wild-type plants, and a PCR was performed using gene-specific primers. PCR generated the predicted amplicon (1504 bp) for the gusA gene in transformed plants, but no amplicon in wild-type plants (Figure 5A), confirming the presence of the gusA gene in transgenic plants.

Although multiple copies of a transgene may be useful for overexpression experiments, single-copy transformation is preferred for most applications due to its stability (Meyer, 1998). Song et al. (2012) demonstrated that transgenic plants with high transgene copy numbers could be distinguished from those with low copy numbers using real-time PCR (Bubner and Baldwin, 2004; Ueno et al., 2011; Alvarez and Ordas, 2013). Four independent gusA-positive (PCR) lines were analyzed using quantitative real-time PCR to estimate the transgene copy number of gusA in genomic DNA samples. We normalized the data using the cycle threshold $\left(C_{\mathrm{T}}\right)$ value of $g u s A$, which occurs as a single gene copy in the SN1301 plasmid. Using these standards, the gusA copy number proved to be highly variable in the transgenic plants, but provided values that were approximately multiples (i.e., 1:1:2:3) among the different lines, ranging from 46.33 to 126.98 copies per microgram of genomic DNA (Figure 5B).

The transgenic lines were analyzed by real-time RT-PCR to verify the expression of the gusA gene at the RNA level. The gusA gene was expressed in all four transformants, and the expression levels showed significant differences between the lines, ranging from 75.77 (line 2) to 184.08 (line 4) (Figure 5C). No RNA from the gusA gene was detected in the non-transformed control plants. The real-time PCR transcript data ruled out residual Agrobacteria activity and confirmed true transformation events. These results demonstrated that the target gene had successfully integrated into the plant genome and was stably expressed in transgenic plants, but no significant correlations were found between transgene copy number and GUS activity levels.

\section{CONCLUSION}

By inducing multiple shoots from stem nodes and using the shoot apices as targets for Agrobacterium infection, we successfully established an efficient method of genetic transformation for the Cd/Zn hyperaccumulator S. plumbizincicola and the nonhyperaccumulating ecotype of $S$. alfredii. This callus-free protocol is a simple, highly efficient approach to genetic transformation in species of Sedum. By facilitating genetic manipulation of these plants this transformation method may allow the molecular mechanisms underlying Cd hyperaccumulation to be investigated by RNA interference, CRISPR/Cas9, and gene overexpression. Furthermore, because species of the Sedum genus are crassulacean acid metabolism (CAM) plants, this transformation method may also facilitate investigation into the molecular mechanisms regulating the temporal $\mathrm{CO}_{2}$ pump and perhaps assist in introducing $\mathrm{CAM}$ into $\mathrm{C}_{3}$ crops, improving the efficiency of plant water-use (Borland et al., 2014).

\section{AUTHOR CONTRIBUTIONS}

WX conceived the original screening and research plans. HL performed most of the experiments. HZ provided technical assistance to HL. WX supervised the experiment. HL and WX designed the experiments and analyzed the data. HL, HZ, and WX conceived the project and wrote the article with contributions of all the authors. LW and WX supervised and complemented the writing.

\section{ACKNOWLEDGMENTS}

This work was supported by the National Natural Science Foundation of China (Grant nos. 41325003 and 91117010) and the Knowledge Innovation Programs of CAS (Grant no. KSCX2YW-G053).

\section{SUPPLEMENTARY MATERIAL}

The Supplementary Material for this article can be found online at: http://journal.frontiersin.org/article/10.3389/fpls.2017.01047/ full\#supplementary-material

FIGURE S1 | Schematic representation of the T-DNA region. (A) pSN1301. (B) PMDC139-GFP.

FIGURE S2 | Transformation of Sedum plumbizincicola. (A) Induction of multiple shoots. (B) Selection of explants using hygromycin. (C) Root induction on selective medium without phytohormones. (D) GUS staining of putative transgenic plants.

FIGURE S3 | Testing Sedum alfredii for sensitivity to kanamycin and hygromycin. (A) The effect of varying kanamycin concentration on the growth of explants. (B) The effect of varying hygromycin concentration on the growth of explants. 


\section{REFERENCES}

Alvarez, J. M., and Ordas, R. J. (2013). Stable Agrobacterium-mediated transformation of maritime pine based on kanamycin selection. ScientificWorldJournal. 2013:681792. doi: 10.1155/2013/681792

An, X., Wang, B., Liu, L. J., Jiang, H., Chen, J., Ye, S. T., et al. (2014). Agrobacterium-mediated genetic transformation and regeneration of transgenic plants using leaf midribs as explants in ramie [Boehmeria nivea (L.) Gaud]. Mol. Biol. Rep. 41, 3257-3269. doi: 10.1007/s11033-014-3188-4

Bert, V., Meerts, P., Saumitou-Laprade, P., Salis, P., Gruber, W., and Verbruggen, N. (2003). Genetic basis of Cd tolerance and hyperaccumulation in Arabidopsis halleri. Plant Soil 249, 9-18. doi: 10.1023/A:1022580325301

Borland, A. M., Hartwell, J., Weston, D. J., Schlauch, K. A., Tschaplinski, T. J., Tuskan, G. A., et al. (2014). Engineering crassulacean acid metabolism to improve water-use efficiency. Trends Plant Sci. 19, 327-338. doi: 10.1016/j. tplants.2014.01.006

Bubner, B., and Baldwin, I. T. (2004). Use of real-time PCR for determining copy number and zygosity in transgenic plants. Plant Cell Rep. 23, 263-271. doi: 10.1007/s00299-004-0859-y

Bull, S. E., Owiti, J. A., Niklaus, M., Beeching, J. R., Gruissem, W., and Vanderschuren, H. (2009). Agrobacterium-mediated transformation of friable embryogenic calli and regeneration of transgenic cassava. Nat. Protoc. 4, 1845-1854. doi: 10.1038/nprot.2009.208

Burgos, L., and Alburquerque, N. (2003). Ethylene inhibitors and low kanamycin concentrations improve adventitious regeneration from apricot leaves. Plant Cell Rep. 21, 1167-1174. doi: 10.1007/s00299-003-0625-6

Cao, D., Zhang, H. Z., Wang, Y. D., and Zheng, L. N. (2014). Accumulation and distribution characteristics of zinc and cadmium in the hyperaccumulator plant Sedum plumbizincicola. Bull. Environ. Contam. Toxicol. 93, 171-176. doi: 10.1007/s00128-014-1284-8

Castelblanque, L., Garcia-Sogo, B., Pineda, B., and Moreno, V. (2010). Efficient plant regeneration from protoplasts of Kalanchoe blossfeldiana via organogenesis. Plant Cell Tissue Organ. Cult. 100, 107-112. doi: 10.1007/ s11240-009-9617-8

Castillo, F. J. (1996). Antioxidative protection in the inducible CAM plant Sedum album $\mathrm{L}$ following the imposition of severe water stress and recovery. Oecologia 107, 469-477. doi: 10.1007/Bf00333937

Clemens, S. (2001). Molecular mechanisms of plant metal tolerance and homeostasis. Planta 212, 475-486. doi: 10.1007/s004250000458

Dalcorso, G., Fasani, E., and Furini, A. (2013). Recent advances in the analysis of metal hyperaccumulation and hypertolerance in plants using proteomics. Front. Plant Sci. 4:280. doi: 10.3389/fpls.2013.00280

D'Amato, F. (1977). “Cytogenetics of differentiation in tissue and cell cultures," in Applied and Fundamental Aspects of Plant Cell, Tissue and Organ Culture, eds J. Reinert and Y. P. S. Bajaj (Berlin: Springer-Verlag Press), 343-357.

Datta, S. K., Peterhans, A., Datta, K., and Potrykus, I. (1990). Genetically engineered fertile indica-rice recovered from protoplasts. Nat. Biotechnol. 8, 736-740. doi: 10.1038/nbt0890-736

Deinlein, U., Weber, M., Schmidt, H., Rensch, S., Trampczynska, A., Hansen, T. H., et al. (2012). Elevated nicotianamine levels in Arabidopsis halleri roots play a key role in zinc hyperaccumulation. Plant Cell 24, 708-723. doi: 10.1105/tpc. 111.095000

Deng, D. M., Shu, W. S., Zhang, J., Zou, H. L., Lin, Z., Ye, Z. H., et al. (2007). Zinc and cadmium accumulation and tolerance in populations of Sedum alfredii. Environ. Pollut. 147, 381-386. doi: 10.1016/j.envpol.2006.05.024

Dobos, E., Danos, B., and Laszlobencsik, A. (1994). Callus induction and shoot regeneration in Sempervivum tectorum. Plant Cell Tissue Organ. Cult. 36, 141-143. doi: 10.1007/BF00048325

Fan, C. H., Pu, N., Wang, X. P., Wang, Y. J., Fang, L., Xu, W. R., et al. (2008). Agrobacterium-mediated genetic transformation of grapevine (Vitis vinifera $\mathrm{L}$.) with a novel stilbene synthase gene from Chinese wild Vitis pseudoreticulata. Plant Cell Tissue Organ. Cult. 92, 197-206. doi: 10.1007/s11240-007-9324-2

Hanikenne, M., and Nouet, C. (2011). Metal hyperaccumulation and hypertolerance: a model for plant evolutionary genomics. Curr. Opin. Plant Biol. 14, 252-259. doi: 10.1016/j.pbi.2011.04.003

Hanikenne, M., Talke, I. N., Haydon, M. J., Lanz, C., Nolte, A., Motte, P., et al. (2008). Evolution of metal hyperaccumulation required cis-regulatory changes and triplication of HMA4. Nature 453, 391-395. doi: 10.1038/nature06877
Jefferson, R. A., Kavanagh, T. A., and Bevan, M. W. (1987). GUS fusions: betaglucuronidase as a sensitive and versatile gene fusion marker in higher plants. EMBO J. 6, 3901-3907.

Karami, O., Esna-Ashari, M., Kurdistani, G. K., and Aghavaisi, B. (2009). Agrobacterium-mediated genetic transformation of plants: the role of host. Biol. Plant. 53, 201-212. doi: 10.1007/s10535-009-0041-z

Larkin, P. J., and Scowcroft, W. R. (1981). Somaclonal variation - a novel source of variability from cell-cultures for plant improvement. Theor. Appl. Genet. 60, 197-214. doi: 10.1007/BF02342540

Li, Z., Wu, L. H., Hu, P. J., Luo, Y. M., and Christie, P. (2013). Copper changes the yield and cadmium/zinc accumulation and cellular distribution in the cadmium/zinc hyperaccumulator Sedum plumbizincicola. J. Hazard. Mater. 261, 332-341. doi: 10.1016/j.jhazmat.2013.07.050

Liu, H. J., Xu, Y., Liu, Y. J., and Liu, C. Z. (2006). Plant regeneration from leaf explants of Rhodiola fastigiata. In Vitro Cell. Dev. Biol. Plant 42, 345-347. doi: 10.1079/IVP2006773

Liu, L., Wu, L., Li, N., Luo, Y., Li, S., Li, Z., et al. (2011). Rhizosphere concentrations of zinc and cadmium in a metal contaminated soil after repeated phytoextraction by Sedum plumbizincicola. Int. J. Phytoremediation 13, 750-764. doi: 10.1080/15226514.2010.525558

Liu, S. Z., Liu, W., Jang, Y. L., Zheng, X. T., Wang, X. L., and Hu, W. R. (2012). Comparison on four extraction methods of genomic DNA from two ecotypes of Sedum alfredii. J. Guangzhou Univ. 11, 27-31.

Livak, K. J., and Schmittgen, T. D. (2001). Analysis of relative gene expression data using real-time quantitative PCR and the $2^{-}-\Delta \Delta$ CT method. Methods 25 , 402-408. doi: 10.1006/meth.2001.1262

Meyer, P. (1998). "Stabilities and instabilities in transgene expression," in Transgenic Plant Research, ed. K. Lindsey (Amsterdam: Harwood Academic Press), 263-275.

Milojevic, J., Tubic, L., Nolic, V., Mitic, N., Calic-Dragosavac, D., Vinterhalter, B., et al. (2012). Hygromycin promotes somatic embryogenesis in spinach. Plant Cell Tissue Organ. Cult. 109, 573-579. doi: 10.1007/s11240-012-0117-x

Nakano, M., Nagai, M., Tanaka, S., Nakata, M., and Godo, T. (2005). Adventitious shoot regeneration and micropropagation of the Japanese endangered Hylotelephium sieboldii (Sweet ex Hook.) H. Ohba and H. sieboldii var. ettyuense (Tomida) H. Ohba. Plant Biotechnol. 22, 221-224. doi: 10.5511/ plantbiotechnology.22.221

Nikulina, V. Y., Gontcharovaa, S. B., Stephensonb, R., and Gontcharov, A. A. (2016). Phylogenetic relationships between Sedum L. and related genera (Crassulaceae) based on ITS rDNA sequence comparisons. Flora 224, 218-229. doi: 10.1016/j.flora.2016.08.003

Nyaboga, E., Tripathi, J. N., Manoharan, R., and Tripathi, L. (2014). Agrobacterium-mediated genetic transformation of yam (Dioscorea rotundata): an important tool for functional study of genes and crop improvement. Front. Plant Sci. 5:463. doi: 10.3389/fpls.2014.00463

Peng, J. S., Ding, G., Meng, S., Yi, H. Y., and Gong, J. M. (2017). Enhanced metal tolerance correlates with heterotypic variation in SpMTL, a metallothioneinlike protein from the hyperaccumulator Sedum plumbizincicola. Plant Cell Environ. doi: 10.1111/pce.12929 [Epub ahead of print].

Prasher, D. C., Eckenrode, V. K., Ward, W. W., Prendergast, F. G., and Cormier, M. J. (1992). Primary structure of the Aequorea victoria green-fluorescent protein. Gene 111, 229-233. doi: 10.1016/0378-1119(92)90691-H

Skirvin, R. M. (1978). Natural and induced variation in tissue-culture. Euphytica 27, 241-266. doi: 10.1007/BF00039141

Smirnoff, N. (1996). "Regulation of crassulacean acid metabolism by water status in the $\mathrm{C}_{3}$ /CAM intermediate Sedum telephium" In Crassulacean Acid Metabolism, Vol. 114, eds K. Winter, J. Andrew, and C. Smith (Berlin: Springer), 176-191. doi: 10.1007/978-3-642-79060-7_12

Smith, R. H., and Nightingale, A. E. (1979). In vitro propagation of Kalanchoe. Hortscience 14:20.

Song, G. Q., Walworth, A., and Hancock, J. F. (2012). Factors influencing Agrobacterium-mediated transformation of switchgrass cultivars. Plant Cell Tissue Organ. Cult. 108, 445-453. doi: 10.1007/s11240-011-0056-y

Stein, R. J., Höreth, S., de Melo, J. R., Syllwasschy, L., Lee, G., Garbin, M. L., et al. (2017). Relationships between soil and leaf mineral composition are element-specific, environment-dependent and geographically structured in the emerging model Arabidopsis halleri. New Phytol. 213, 1274-1286. doi: 10.1111/ nph.14219 
Sujatha, M., and Sailaja, M. (2005). Stable genetic transformation of castor (Ricinus communis L.) via Agrobacterium tumefaciens-mediated gene transfer using embryo axes from mature seeds. Plant Cell Rep. 23, 803-810. doi: 10.1007/ s00299-004-0898-4

Thiede, J., and Eggli, U. (2007). "Crassulaceae," in The Families and Genera of Vascular Plants, Vol. IX, ed. K. Kubitzki (Berlin: Springer press), 83-118.

Ueno, D., Milner, M. J., Yamaji, N., Yokosho, K., Koyama, E., Clemencia Zambrano, M., et al. (2011). Elevated expression of TcHMA3 plays a key role in the extreme $\mathrm{Cd}$ tolerance in a Cd-hyperaccumulating ecotype of Thlaspi caerulescens. Plant J. 66, 852-862. doi: 10.1111/j.1365-313X.2011.04548.x

van der Ent, A., Baker, A. J. M., Reeves, R. D., Pollard, A. J., and Schat, H. (2013). Hyperaccumulators of metal and metalloid trace elements: facts and fiction. Plant Soil 362, 319-334. doi: 10.1007/s11104-012-1287-3

Verbruggen, N., Hermans, C., and Schat, H. (2009). Molecular mechanisms of metal hyperaccumulation in plants. New Phytol. 181, 759-776. doi: 10.1111/j. 1469-8137.2008.02748.x

Verbruggen, N., Juraniec, M., Baliardini, C., and Meyer, C. L. (2013). Tolerance to cadmium in plants: the special case of hyperaccumulators. Biometals 26, 633-638. doi: 10.1007/s10534-013-9659-6

Wang, H. H., Wang, C. T., Liu, H., Tang, R. J., and Zhang, H. X. (2011). An efficient Agrobacterium-mediated transformation and regeneration system for leaf explants of two elite aspen hybrid clones Populus alba $\mathrm{x}$ P. berolinensis and Populus davidiana x P. bolleana. Plant Cell Rep. 30, 2037-2044. doi: 10.1007/ s00299-011-1111-1

Wang, L., Mei, Q., and Wan, D. (2014). Simultaneous determination by HPLC of quercetin and kaempferol in three Sedum medicinal plants harvested in different seasons. J. Chromatogr. Sci. 52, 334-338. doi: 10.1093/chromsci/ bmt035

Wilmink, A., and Dons, J. J. M. (1993). Selective agents and marker genes for use in transformation of monocotyledonous plant. Plant Mol. Biol. Rep. 11, 165-185. doi: $10.1007 / \mathrm{BF} 02670474$
Winter, K., and Holtum, J. A. M. (2014). Facultative crassulacean acid metabolism (CAM) plants: powerful tools for unravelling the functional elements of CAM photosynthesis. J. Exp. Bot. 65, 3425-3441. doi: 10.1093/jxb/ eru063

Wu, L. H., Liu, Y. J., Zhou, S. B., Guo, F. G., Bi, D., Guo, X. H., et al. (2013). Sedum plumbizincicola X.H. Guo et S.B. Zhou ex L.H. Wu (Crassulaceae): a new species from Zhejiang Province, China. Plant Syst. Evol. 299, 487-498. doi: 10.1007/s00606-012-0738-x

Yang, X. E., Long, X. X., Ye, H. B., He, Z. L., Calvert, D. V., and Stoffella, P. J. (2004). Cadmium tolerance and hyperaccumulation in a new Zn-hyperaccumulating plant species (Sedum alfredii Hance). Plant Soil 259, 181-189. doi: 10.1023/B: Plso.0000020956.24027.F2

Yoon, E. S., Jeong, J. H., and Choi, Y. E. (2002). Recovery of Basta-resistant Sedum erythrostichum via Agrobactecterium-mediated transformation. Plant Cell Rep. 21, 70-75. doi: 10.1007/s00299-002-0485-5

Zhao, S. J., Zhang, Z. C., Gao, X., Tohsun, G., and Qiu, B. S. (2009). Plant regeneration of the mining ecotype Sedum alfredii and cadmium hyperaccumulation in regenerated plants. Plant Cell Tissue Organ. Cult. 99, 9-16. doi: 10.1007/s11240-009-9570-6

Conflict of Interest Statement: The authors declare that the research was conducted in the absence of any commercial or financial relationships that could be construed as a potential conflict of interest.

Copyright (C) $2017 \mathrm{Liu}, \mathrm{Zhao}, \mathrm{Wu}$ and Xu. This is an open-access article distributed under the terms of the Creative Commons Attribution License (CC BY). The use, distribution or reproduction in other forums is permitted, provided the original author(s) or licensor are credited and that the original publication in this journal is cited, in accordance with accepted academic practice. No use, distribution or reproduction is permitted which does not comply with these terms. 